\title{
Influence of Hydrogen Bonding on the Melt Rheology of Polypropylene
}

\author{
Sahil Gupta ${ }^{1 \dagger}$, Xuepei Yuan ${ }^{2}$, T. C. Mike Chung ${ }^{2}$, M. Cakmak ${ }^{1}$ and R. A. Weiss ${ }^{1 *}$ \\ ${ }^{1}$ Department of Polymer Engineering, The University of Akron, Akron, OH 44325 \\ ${ }^{2}$ Department of Materials Science and Engineering, The Pennsylvania State University, \\ University Park, PA, 16802
}

\begin{abstract}
The rheological behavior of hydroxyl-functionalized polypropylene (PPOH) copolymers modified with up to 3.9 mol\% hydroxyl groups was compared with unmodified polypropylene (PP) in the melt state. The hydroxyl groups interacted via hydrogen (H-) bonding, the strength of which increased with increasing hydroxyl concentration. The hydrogen bonds persisted at temperatures as high as $250^{\circ} \mathrm{C}$, even though the $\mathrm{H}$-bonding strength decreased with increasing temperature. A direct consequence of H-bonding was an increase in the elasticity, viscosity and relaxation time of the PPOH copolymers compared to PP, and also an increase in these properties with increasing hydroxyl concentration. The zero-shear viscosity exhibited a power-law relationship with the hydroxyl concentration, $\eta_{0} \propto\left[\mathrm{M}_{\mathrm{v}}\right]^{3.6}[\mathrm{OH}]^{2}$, which was found to be consistent with the predictions from Leibler-Rubinstein-Colby (LRC) theory for associating polymers. The PPOH copolymers exhibited apparent molecular weights $2-8$ times higher than the actual molecular weights. The PPOH copolymer with 3.9 mol\% hydroxyl groups displayed a gel-like behavior that suggested the formation of an elastic network in the melt presumably due to the phase separation of $\mathrm{H}$-bonded $\mathrm{OH}$ groups into nanoclusters. The network, however, was weak since non-Newtonian viscous flow occurred under nonlinear deformations.
\end{abstract}


†Present address: Parker Hannifin Corporation, Parflex Division, 1300 N. Freedom St., Ravenna, OH 44266

*corresponding author: R. A. Weiss, Dept. of Polymer Engineering, 250 S. Forge St., The University of Akron, Akron, OH 44325-0301; Email: rweiss@ uakron.edu. 


\section{Introduction}

Metallized biaxially oriented polypropylene (BOPP) represents the state-of-the-art polymer for high energy capacitor film, ${ }^{1}$ largely due to its high breakdown voltage (600-750 $\mathrm{V} / \mu \mathrm{m}$ for $\sim 10 \mu \mathrm{m}$ thick films $),{ }^{2}$ very low dielectric loss $(<0.01 \%)$ and good self-healing characteristics. $^{3}$ BOPP, however, has a low dielectric constant $(\sim 2.2)$ that limits the stored energy density to $3-5 \mathrm{~J} / \mathrm{cm}^{3}$ at breakdown. ${ }^{2}$ The dielectric constant of polypropylene (PP) can be increased by incorporation of functional side-groups that are highly polarizable and can align in an electric field. Yuan et al. ${ }^{4}$ recently reported the synthesis of hydroxyl-functionalized isotactic polypropylene copolymers $(\mathrm{PPOH})$ that exhibit energy densities 2-3 times that of BOPP. Incorporation of the hydroxyl containing comonomer also affected the thermal properties, crystal morphology and crystallization behavior of PP. ${ }^{5,6}$

Current research on $\mathrm{PPOH}$ copolymers involves melt casting and biaxial orientation of film for consideration as an alternative to PP in high energy density capacitors. That requires knowledge of how the hydroxyl-comonomer concentration affects the melt rheology, and ultimately, the processing of the $\mathrm{PPOH}$ copolymers into dielectric films. Apart from understanding the processing behavior, it is also useful to model the effect of hydroxyl group concentration on the rheological properties so that predictions can be made to facilitate design of experiments for processing operations. It is well-known from the rheological studies of associating polymers that intermolecular interactions such as H-bonding or dipole-dipole can strongly affect the flow behavior and processability of polymers. ${ }^{7}$ However, a simplistic model to predict the rheological properties as a function of associating group concentration is still elusive. In this paper, we discuss the rheological behavior of PPOH polymers and validate a model to predict the effect of hydroxyl concentration on the melt viscosity of polypropylene. 


\section{Experimental Details}

Materials. The synthesis and structure of the PPOH copolymers are shown in Figure 1, and the details are described elsewhere. ${ }^{4}$ Copolymers of propylene and undecenyloxytrimethylsilane were prepared by heterogeneous Ziegler-Natta (Z-N) polymerization, and the intermediate silane was hydrolyzed under acidic conditions to form the corresponding $\mathrm{PPOH}$ copolymer. The reactivity ratios for the copolymerization $\left(r_{1}=68\right.$ for propylene and $r_{2}=0.032$ for the comonomer) indicate that the $\mathrm{PPOH}$ samples are composed of a mixture of compositions ranging from propylene-rich chains formed at the early stages of the polymerization and comonomer-rich chains formed at high conversion. ${ }^{6}$ The nomenclature for the samples, $\mathrm{PPOH}-\mathrm{x}$, where $\mathrm{x}$ is the molar concentration of the $\mathrm{OH}$-containing side-chains, is the same used in our previous paper. ${ }^{6}$ The concentration $\mathrm{x}$ ranged from 1.3 to $3.9 \mathrm{~mol} \%$, Table 1 . The PP sample was prepared using the same synthetic procedure, but without the comonomer.

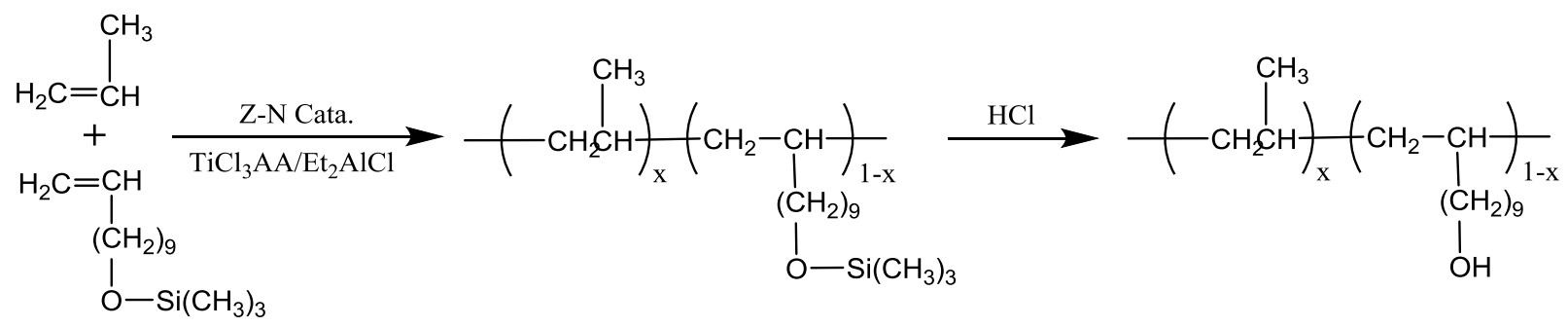

Figure 1. Synthesis of PPOH copolymers. 
Table 1. Molecular weight, thermal and rheological characteristics of PP and PPOH copolymers.

\begin{tabular}{|c|c|c|c|c|c|c|c|c|c|c|c|c|c|c|c|c|c|}
\hline Polymer & \begin{tabular}{|l}
{$[\mathrm{OH}]^{1}$} \\
$(\mathrm{~mol} \%)$ \\
\end{tabular} & $\begin{array}{c}\mathrm{M}_{\mathrm{n}}^{2} \\
(\mathrm{kDa}) \\
\end{array}$ & $\begin{array}{c}\mathrm{M}_{\mathrm{w}}{ }^{2} \\
(\mathrm{kDa})\end{array}$ & $\begin{array}{c}\mathrm{M}_{\mathrm{z}}^{2} \\
(\mathrm{kDa})\end{array}$ & $\mathrm{M}_{\mathrm{w}} / \mathrm{M}_{\mathrm{n}}$ & $\mathrm{M}_{\mathrm{z}} / \mathrm{M}_{\mathrm{w}}$ & $\begin{array}{c}\mathrm{M}_{\mathrm{v}}^{3} \\
(\mathrm{kDa})\end{array}$ & $\begin{array}{c}\mathrm{T}_{\mathrm{g}}^{4} \\
\left({ }^{\circ} \mathrm{C}\right) \\
\end{array}$ & $\begin{array}{l}\mathrm{T}_{\mathrm{m}}^{5} \\
\left({ }^{\circ} \mathrm{C}\right)\end{array}$ & $\mathrm{m}^{\prime 6}$ & $\mathrm{~m}^{\prime 7}$ & $\begin{array}{l}\tau^{8} \\
(\mathrm{~s})\end{array}$ & $\begin{array}{c}\Delta \mathrm{E}^{9} \\
(\mathrm{~kJ} / \mathrm{mol})\end{array}$ & $\begin{array}{c}\eta_{0}\left(\times 10^{3}\right)^{10} \\
(\mathrm{~Pa}-\mathrm{s})\end{array}$ & $\begin{array}{l}\lambda^{5} \\
(\mathrm{~s})\end{array}$ & $n^{5}$ & $\begin{array}{l}M_{\text {app }}^{11} \\
(\mathrm{kDa})\end{array}$ \\
\hline $\mathrm{PP}$ & 0 & 38 & 385 & 1479 & 10.2 & 3.8 & 276 & -4.2 & 163.0 & 1.23 & 0.82 & 0.05 & 38.6 & 4.3 & 31.7 & 0.85 & 385 \\
\hline РPOH-1.3 & 1.3 & 16 & 243 & 1405 & 14.8 & 5.8 & 188 & -2.0 & 158.0 & 0.86 & 0.69 & 0.13 & 39.7 & 15.7 & 156.3 & 0.75 & 552 \\
\hline РPOH-1.4 & 1.4 & 27 & 488 & 2235 & 17.9 & 4.6 & 219 & -1.7 & 157.0 & 0.73 & 0.60 & 0.70 & 43.7 & 44.5 & 84.6 & 0.59 & 737 \\
\hline PPOH-1.7 & 1.7 & - & - & - & - & - & 388 & 0.0 & 157.0 & 0.68 & 0.57 & 1.13 & 43.1 & 201.5 & 570.4 & 0.48 & 1121 \\
\hline РPOH-3.2 & 3.2 & - & - & - & - & - & 311 & 0.0 & 157.1 & 0.60 & 0.53 & 15.50 & 52.4 & 407.7 & 400.1 & 0.43 & 1363 \\
\hline РPOH-3.9 & 3.9 & - & - & - & - & - & 301 & 0.3 & 157.0 & 0.45 & 0.45 & - & 48.9 & 3040.0 & 1641.0 & 0.20 & 2382 \\
\hline
\end{tabular}

${ }^{\mathrm{T}}$ from ${ }^{\mathrm{l}} \mathrm{H}-\mathrm{NMR}$ spectra

${ }^{2}$ from HTGPC with PS standards; PPOH-1.7, PPOH-3.2 and PPOH-3.9 could not be dissolved

${ }^{3}$ calculated from $[\eta]=\mathrm{K} \cdot \mathrm{M}_{\mathrm{v}}{ }^{\alpha}$, where $\mathrm{K}=1.05 \times 10^{-5} \mathrm{~L} / \mathrm{g}$ and $\alpha=0.8$. [ $\left.\eta\right]$ was measured in decalin at $135^{\circ} \mathrm{C}{ }^{8}$

${ }^{4}$ from DSC, heating @ $50^{\circ} \mathrm{C} / \mathrm{min}$

${ }^{5}$ from DSC, heating @ $10{ }^{\circ} \mathrm{C} / \mathrm{min}$

${ }^{6}$ from the low frequency slope of $\mathrm{G}^{\prime}$ vs $\omega$ (Figure 5)

${ }^{7}$ from the low frequency slope of G" vs $\omega$ (Figure 5)

${ }^{8}$ from the inverse of the cross-over frequency of $\mathrm{G}^{\prime}$ and $\mathrm{G}^{\prime \prime}$

${ }^{9}$ calculated from equation (4)

${ }^{10}$ from fit of Carreau model (equation (5)) to the shear viscosity data (Figure 8(a))

${ }^{11}$ calculated from equation (8) 
Characterization. The viscosity-average molecular weight $\left(\mathrm{M}_{\mathrm{v}}\right)$ was calculated from the intrinsic viscosity of the polymer measured with a Cannon-Ubbelohde viscometer using decahydronaphthalene (Decalin) solutions at $135^{\circ} \mathrm{C}$. The Mark-Houwink relationship for polypropylene was used to estimate $\mathrm{M}_{\mathrm{v}}{ }^{8}$

$$
[\eta]=K M_{v}^{\alpha}
$$

where $\mathrm{K}=1.05 \times 10^{-5} \mathrm{~L} / \mathrm{g}$ and $\alpha=0.8$. The number-average $\left(\mathrm{M}_{\mathrm{n}}\right)$, weight-average $\left(\mathrm{M}_{\mathrm{w}}\right)$ and zaverage $\left(M_{z}\right)$ molecular weights, and the polydispersities, $M_{w} / M_{n}$ and $M_{z} / M_{w}$, were measured by high temperature gel permeation chromatography (HTGPC) at the University of Massachusetts, Amherst. For HTGPC measurements, $4 \mathrm{mg}$ of polymer was dissolved in $1 \mathrm{~mL}$ trichlorobenzene (containing 0.1 wt $\%$ each of $\operatorname{Irganox}^{\circledR} 1010$ and Irgafos ${ }^{\circledR} 168$ antioxidants) at $145^{\circ} \mathrm{C}$ and the solution was analyzed in the GPC at $135^{\circ} \mathrm{C}$. The instrument was calibrated using polystyrene standards. Note that for both the intrinsic viscosity and GPC measurements, the size of the polymer chain in solution is being measured and the molecular weight is calculated from known correlations between the two properties. Those correlations are not known for $\mathrm{PPOH}$, and even though the hydroxyl concentrations were low, hydrogen bonding between hydroxyl groups can affect the conformation of the polymer chains. Thus, using the Mark Houwink equation for PP and a polystyrene calibration for the GPC introduces error in that determination of the $\mathrm{PPOH}$ molecular weights reported in Table 1. For dilute solutions, one might expect that intra-chain Hbonding will be favored, which is expected to decrease the radius of gyration of the chains. That would produce an underestimation of the molecular weights reported in Table 1 . We have assumed that the error in the molecular weight determination introduced by the H-bonding was small, which may be justified based on the expected weakening of the $\mathrm{H}$-bonds at $135^{\circ} \mathrm{C}$. 
Polymer films were compression molded at $200^{\circ} \mathrm{C}$, cooled to room temperature at $\sim 40^{\circ} \mathrm{C} / \mathrm{min}$ and and thoroughly dried by annealing under vacuum at $80^{\circ} \mathrm{C}$ for $24 \mathrm{~h}$. Hydrogenbonding interactions were measured by Fourier transform infrared spectroscopy (FTIR) from 23 - $250{ }^{\circ} \mathrm{C}$ using a Thermo Scientific Nicolet 380 FTIR equipped with an external heating accessory. The sample was a thin polymer film $(\sim 20 \mu \mathrm{m})$ sandwiched between $2 \mathrm{KBr}$ cover slips obtained from International Crystal Laboratories. The temperature was increased step-wise from $23^{\circ} \mathrm{C}$ to $250^{\circ} \mathrm{C}$ and allowed to equilibrate at each temperature before collecting the IR spectra, which were measured by averaging 32 scans with a resolution of $4 \mathrm{~cm}^{-1}$.

Linear viscoelastic properties were measured with a TA Instruments ARES G2 rheometer using small amplitude oscillatory shear (SAOS) from $165-250{ }^{\circ} \mathrm{C}$ at frequencies $(\omega)=0.1-$ $100 \mathrm{rad} / \mathrm{s}$ and strain amplitudes of $3-8 \%$ with a $25 \mathrm{~mm}$ parallel-plate fixture. Strain-sweeps were carried out to determine the LVE limit, and mastercurves were constructed for a reference temperature, $T_{r}=200^{\circ} \mathrm{C}$, using time-temperature superposition (TTS). Steady shear experiments were carried out at $200^{\circ} \mathrm{C}$ covering shear rates from $10^{-4}-1 \mathrm{~s}^{-1}$ with the ARES G2 rheometer using a $25 \mathrm{~mm}$ cone-and-plate fixture with a cone angle of $0.04 \mathrm{rad}$.

\section{Results and Discussion}

Molecular Weights. The molecular weight averages and the thermal properties of the polymers are summarized in Table $1 . \mathrm{M}_{\mathrm{v}}$ for the polymers ranged from $188-388 \mathrm{kDa}$. The HTGPC data were not obtained for the PPOH-x copolymers with $\mathrm{x} \geq 1.7$ because they were not completely soluble in trichlorobenzene, which was the carrier solvent used in the HTGPC. For the other polymers, the peak on the GPC curve was highly asymmetric (not shown). The limited HTGPC data indicate that the polydispersity index $\left(\mathrm{PDI}=\mathrm{M}_{\mathrm{w}} / \mathrm{M}_{\mathrm{n}}\right)$ of the copolymer increased 
with increasing $\mathrm{OH}$ concentration, although the same effect was not observed on $\mathrm{M}_{\mathrm{z}} / \mathrm{M}_{\mathrm{w}}$ which varied between $3.8-5.8$. The molecular weights of all the samples were very high such that it is doubtful that differences in molecular weight account for the differences in the thermal properties of the polymers given in Table 1. Similarly, the PDI of the three polymers for which it was calculated were all quite broad and the differences probably did not affect the thermal transitions.

Rheological properties are sensitive to molecular weight, and elasticity and viscosity typically increase with increasing molecular weight. The zero-shear viscosity $\left(\eta_{0}\right)$ scales with the $\left(\mathbf{M}_{\mathrm{w}}\right)^{3.4}$ and the zero-first normal stress coefficient $\left(\psi_{1,0}\right)$ scales with $\mathbf{M}_{\mathrm{w}}{ }^{7 \cdot} \cdot{ }^{9}$ Broadening the molecular weight distribution (MWD) increases the polymer elasticity and viscosity at terminal frequencies, increases the terminal relaxation time, and results in a more pronounced shearthinning behavior. ${ }^{9}$ Although some reports conclude that $\eta_{0}$ is not affected by the MWD, ${ }^{10,11}$ other reports claim that $\eta_{0}$ increases as the MWD broadens. ${ }^{12-14}$ To the best of our knowledge, the dependence on PDI of $\psi_{1,0}$ has not been experimentally measured.

Hydrogen Bonding Interactions. Hydrogen ( $\mathrm{H}-)$ bonding between the $\mathrm{OH}$ groups in the PPOH copolymers was evident from a comparison of the room temperature FTIR absorption spectra for PP and the PPOH copolymers in the spectral region $3700-3100 \mathrm{~cm}^{-1}$, where the O-H stretching vibrations occur, Figure 2(a). The low intensity peak at $3637 \mathrm{~cm}^{-1}$ corresponds to the stretching vibration of free, non-hydrogen bonded $\mathrm{OH}$ groups and the higher intensity, broad absorption at $3332 \mathrm{~cm}^{-1}$ corresponds to the stretching vibration of H-bonded $\mathrm{OH}$ groups. ${ }^{15}$ Both absorptions are absent in the PP sample. 

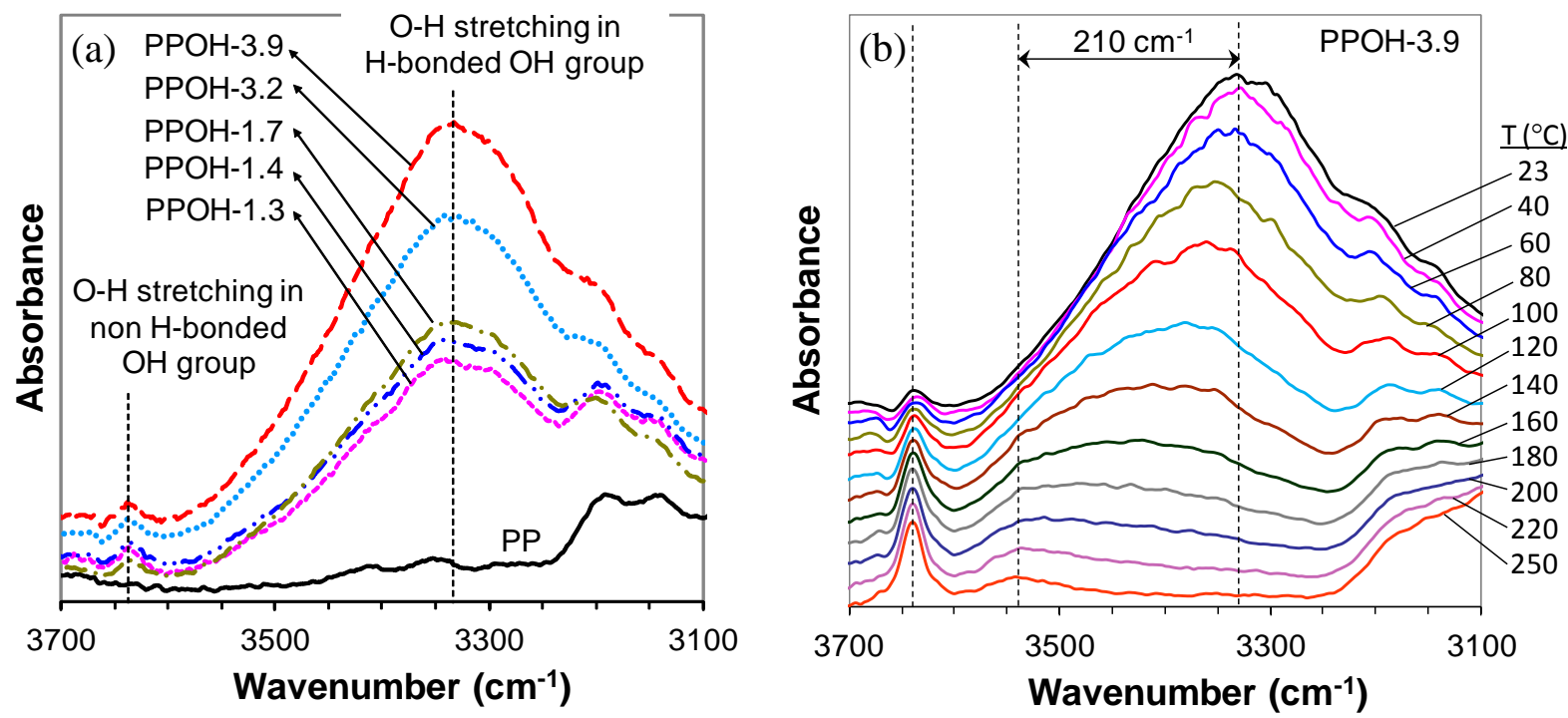

Figure 2. (a) FTIR spectra of PP and PPOH copolymers at room temperature for the spectral region of $3100-3700 \mathrm{~cm}^{-1}$. (b) FTIR spectrum of PPOH-3.9 from $23-250{ }^{\circ} \mathrm{C}$. The spectra of other PPOH copolymers were qualitatively similar. The peaks are shifted vertically for clarity.

The energy of the hydrogen bond is sensitive to the directionality of the bond between the proton donor and the proton acceptor, represented by the bond angle $\alpha$ in Figure 3. The maximum energy of the hydrogen bond occurs for a linear orientation $\left(\alpha=180^{\circ}\right)$ and the bond energy falls off exponentially with decreasing bond angle. The broadening of the $\mathrm{H}$-bonded $\mathrm{O}-\mathrm{H}$ band in Figure 2 is a consequence of a broad distribution of hydrogen bond angles that produces a similar distribution of bond energies (i.e., IR frequencies). The hydrogen bond also affects the bond lengths associated with the donor and acceptor species, which also affects the bond energy of the $\mathrm{O}-\mathrm{H} .{ }^{16}$ 


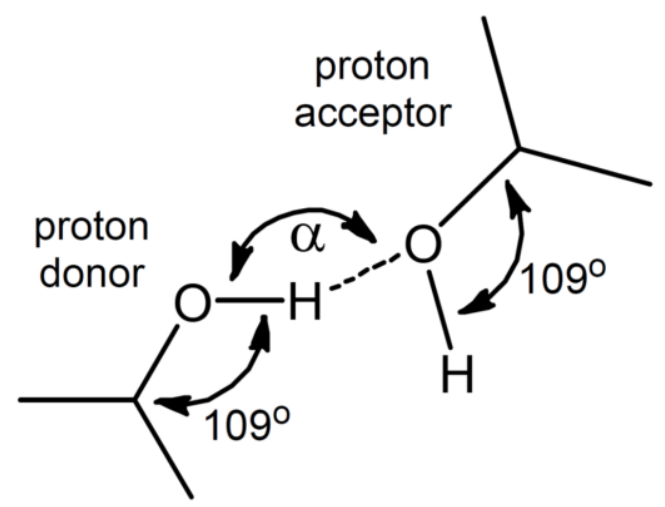

Figure 3. Hydrogen bonded hydroxyl groups. $\alpha$ denotes the angle of the hydrogen bond (represented by the dashed line).

The intensity and area of the $3332 \mathrm{~cm}^{-1}$ peak increased relative to the $3637 \mathrm{~cm}^{-1}$ peak as the concentration of $\mathrm{OH}$ in the polymer increased, Figure 2(a). The ratio of $\mathrm{H}$-bonded $\mathrm{OH}$ groups to free $\mathrm{OH}$ groups was calculated from the ratio of the area under their respective peaks assuming that both the bands had the same absorption coefficient. The areas $\left(\mathrm{A}_{\mathrm{i}}\right.$, where $i$ was the peak frequency in $\mathrm{cm}^{-1}$ ) were calculated by deconvoluting the $\mathrm{O}-\mathrm{H}$ peaks using a Gaussian function and a constant baseline. The ratio of the concentrations of $\mathrm{H}$-bonded $\mathrm{OH}$ groups and free $\mathrm{OH}$ group, $\mathrm{A}_{3332} / \mathrm{A}_{3637}$, increased with increasing hydroxyl concentration, see Figure 4(a), though for all PPOH-x copolymers the percentage of $\mathrm{OH}$ groups that were $\mathrm{H}$-bonded at room temperature $\left(f_{O-H-O}=\frac{\left[\frac{A_{3332}}{A_{3637}}\right]}{\left[1+\frac{A_{3332}}{A_{3637}}\right]} \times 100 \%\right)$ was at least $99 \%$. 

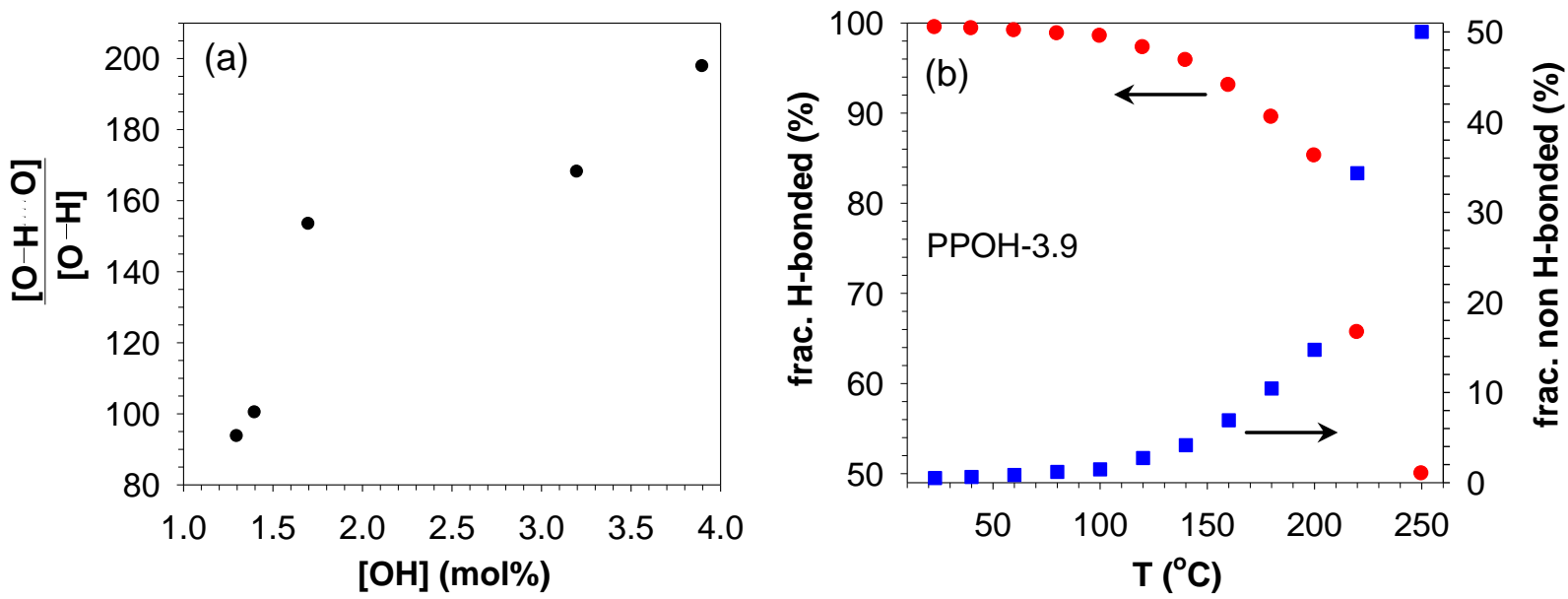

Figure 4. Ratio of $\mathrm{H}$-bonded $\mathrm{OH}$ groups to free, non-H-bonded $\mathrm{OH}$ groups (a) as a function of hydroxyl concentration at room temperature, (b) as a function of temperature for PPOH-3.9.

The strength of the H-bonds decreased with increasing temperature, as was evident from the shift of the IR bands for the H-bonded hydroxyl groups in Figure 2(b) to higher frequencies as the temperature increased. For example, the $\mathrm{H}$-bonded $\mathrm{O}-\mathrm{H}$ stretching peak exhibited a spectral shift of $210 \mathrm{~cm}^{-1}$, from $3332 \mathrm{~cm}^{-1}$ to $3542 \mathrm{~cm}^{-1}$ when the temperature increased from $23^{\circ} \mathrm{C}$ at $250^{\circ} \mathrm{C}$. Rozenberg ${ }^{17}$ proposed an empirical relationship between the energy [kJ/mol] of the H-bond and the red-shift, $\Delta \tilde{v}\left[\mathrm{~cm}^{-1}\right]$, between the $\mathrm{H}$-bonded and non-H-bonded stretching vibrations for a variety of $\mathrm{H}-$ bonded complexes, including $\mathrm{O}-\mathrm{H} \cdots \mathrm{O}$.

$$
\Delta \mathrm{H}=1.3[\Delta \tilde{v}]^{1 / 2}
$$

Based on equation (2), the average $\mathrm{H}$-bond strength decreased from $22.7 \mathrm{~kJ} / \mathrm{mol}$ at $23^{\circ} \mathrm{C}$ to 12.7 $\mathrm{kJ} / \mathrm{mol}$ at $250^{\circ} \mathrm{C}$, a decrease of $44 \%$.

The ratio of areas of the $\mathrm{H}$-bonded $\mathrm{O}-\mathrm{H}$ band to the non-H-bonded $\mathrm{O}-\mathrm{H}$ band decreased exponentially with increasing temperature, Figure $4(\mathrm{~b})$, but even at $250^{\circ} \mathrm{C}$ the ratio of the areas of the $\mathrm{H}$-bonded and non-H-bonded absorbances, $\mathrm{A}_{[\mathrm{O}-\mathrm{H} \cdots \mathrm{O}]} / \mathrm{A}_{[\mathrm{O}-\mathrm{H}]}=1$. Those results were due to 
the conversion of $\mathrm{H}$-bonded $\mathrm{OH}$ groups into "free" $\mathrm{OH}$ groups and a decrease in the absorption coefficient for $\mathrm{H}$-bonded $\mathrm{O}-\mathrm{H}$ band with increasing temperature, i.e., decreasing bond strength. ${ }^{18-20}$ Without knowing the temperature dependence of the absorption coefficients of both $\mathrm{OH}$ absorbances, it is not possible to quantitatively determine the conversion of $\mathrm{H}$-bonded $\mathrm{OH}$ groups to free $\mathrm{OH}$ with increasing temperature. However, if one assumes that the two absorptions coefficients have the same or similar temperature dependences, then Figure 4(b) indicates that the percentage of $\mathrm{OH}$ groups that were $\mathrm{H}$-bonded decreased from $100 \%$ at $23^{\circ} \mathrm{C}$ $([\mathrm{O}-\mathrm{H} \cdots \mathrm{O}] /[\mathrm{O}-\mathrm{H}]=196)$ to $50 \%$ at $250^{\circ} \mathrm{C}([\mathrm{O}-\mathrm{H} \cdots \mathrm{O}] /[\mathrm{O}-\mathrm{H}]=1)$. Therefore, the $\mathrm{H}$-bonds in $\mathrm{PPOH}-3.9$ persisted at melt temperatures up to $250^{\circ} \mathrm{C}$, which is somewhat surprising in that one might normally expect the H-bonds to disappear at such high temperatures. That result may be a consequence of the large enthalpic penalty an $\mathrm{OH}$ group accrues by its isolation in the hydrocarbon melt. Similar observations were made for the PPOH-x copolymers with lower hydroxyl concentration (results not shown). H-bonded and non H-bonded O-H stretching peaks from bound and free water also occur in this spectral region, ${ }^{21}$ so the $210 \mathrm{~cm}^{-1}$ shift of the $\mathrm{H}$ bonded $\mathrm{O}-\mathrm{H}$ stretching from $3332 \mathrm{~cm}^{-1}$ at $23^{\circ} \mathrm{C}$ to $3542 \mathrm{~cm}^{-1}$ at $250^{\circ} \mathrm{C}$ may also be due, in part, to the loss of bound water from the PPOH copolymer.

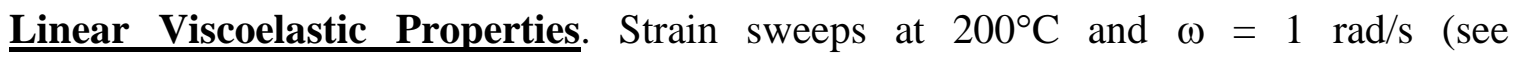
supplementary information) indicated that the linear viscoelastic behavior (LVE) of PP was maintained until about $31 \%$ strain, and the linear range limit decreased for the PPOH copolymers to about $13 \%$ for $\mathrm{PPOH}-3.9$. The greater sensitivity of the $\mathrm{PPOH}$ to strain was due to the $\mathrm{H}-$ bonding interactions and, perhaps, the presence of a nanostructure of hydrogen bonded $\mathrm{OH}$ aggregates for the polymers with higher $\mathrm{OH}$ concentrations, as predicted by the simulations of hydroxyl modified polyethylene by Misra et al. ${ }^{22}$ The presence of a network arising from the 
hydroxyl nanostructure is supported by the small amplitude oscillatory shear (SAOS) data in Figure 5, which shows master curves of the storage $\left(\mathrm{G}^{\prime}\right)$ and loss $\left(\mathrm{G}^{\prime \prime}\right)$ shear moduli at $200^{\circ} \mathrm{C}$ for $\mathrm{PP}$ and some of the PPOH-x copolymers. The master-curves were constructed using timetemperature superposition (TTS) by shifting the isothermal data horizontally along the frequency axis. The TTS was valid for all the polymers indicating thermorheological simplicity.

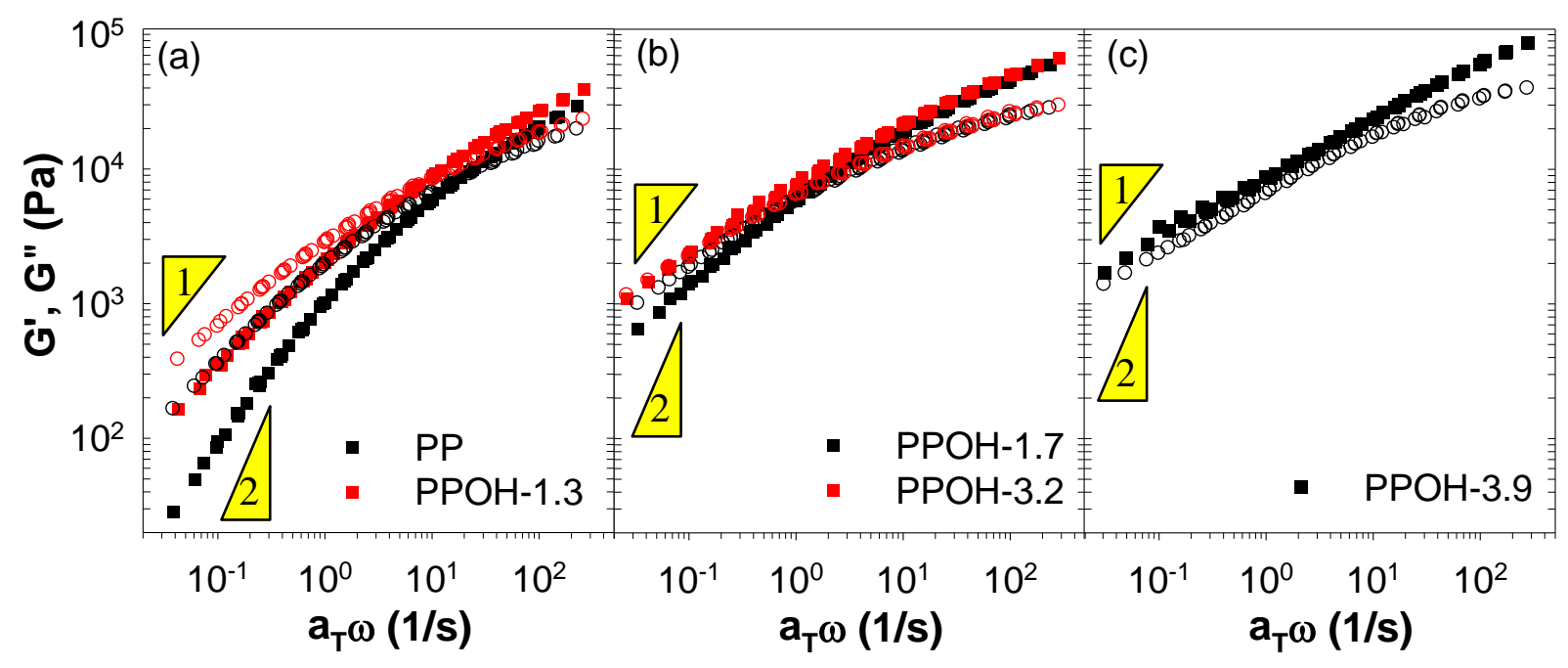

Figure 5. Master-curves for the storage modulus, $\mathrm{G}^{\prime}(\mathbf{\square})$, and loss modulus, $\mathrm{G}^{\prime \prime}(\mathrm{\circ})$, at $200^{\circ} \mathrm{C}$ for $\mathrm{PP}$ and PPOH copolymers: (a) PP and PPOH-1.3; (b) PPOH-1.7 and PPOH-3.2; and (c) PPOH-3.9. The slopes of 2 and 1 for $G^{\prime}$ and $G^{\prime \prime}$, respectively, correspond to terminal linear viscoelastic behavior.

H-bonding had a significant effect on the rheological properties of the PP and PPOH-x melts. $\mathrm{G}^{\prime}$ (the elastic response) and $\mathrm{G}^{\prime \prime}$ (the viscous response) of the polymers shown in Figure 5 increased with increasing $[\mathrm{OH}]$, but much more than would be expected if this were solely a molecular weight effect. For e.g. the $\mathrm{M}_{\mathrm{w}}$ of PP was higher than $\mathrm{PPOH}-1.3$, which indicates that both $\mathrm{G}^{\prime \prime}$ and $\mathrm{G}^{\prime}$ should be higher for PP at any given frequency (recall the earlier discussion in this paper that $\eta_{0} \sim\left(\mathrm{M}_{\mathrm{w}}\right)^{3.4}$ and $\left.\psi_{1,0} \sim \mathrm{M}_{\mathrm{w}}{ }^{7}\right) .{ }^{9}$ However, the dynamic viscosity of PPOH-1.3 
estimated at $\omega=0.1 \mathrm{~s}^{-1}\left(\eta^{\prime}=\mathrm{G}^{\prime \prime} / \omega=6.74 \times 10^{3}\right.$ Pa-s $)$ was almost twice than that for PP $\left(\eta^{\prime}=\right.$ $\left.3.53 \times 10^{3} \mathrm{~Pa}-\mathrm{s}\right)$. The elasticity, represented by $\mathrm{G}^{\prime}$, measured at the same frequency was four times higher for PPOH-1.3 than for PP.

For the PP and the PPOH-x copolymers where $\mathrm{x}<3.9$ the melts at $200^{\circ} \mathrm{C}$ behaved as viscoelastic solids at the higher frequencies $\left(\mathrm{G}^{\prime}>\mathrm{G}^{\prime \prime}\right)$ and viscoelastic liquids at lower frequencies $\left(\mathrm{G}^{\prime \prime}>\mathrm{G}^{\prime}\right)$, Figures $5(\mathrm{a})$ and $5(\mathrm{~b})$. The solid-like behavior was due in part to the transient entanglement network commonly observed with high molecular weight polymers and to the supramolecular network formed by H-bonding of the hydroxyl groups. Terminal behavior, ${ }^{24}$ however, where $\mathrm{G}^{\prime} \propto \omega^{2}$ and $\mathrm{G}^{\prime \prime} \propto \omega$, was not achieved in the flow curves at the experimental temperature and frequency ranges for any of the polymers shown in Figure 5. The low frequency slopes, $\mathrm{m}^{\prime}$ and $\mathrm{m}$ ", calculated from $\mathrm{G}^{\prime}$ and $\mathrm{G}^{\prime \prime}$ respectively, were lower for the PPOH copolymers, see Table 1, and decreased with increasing hydroxyl concentration. Thus, the incorporation of $\mathrm{OH}$ groups shifted the terminal behavior in the $\mathrm{PPOH}$ copolymers to lower frequency (or higher temperature) and increased the terminal relaxation time.

Anomalous behavior was exhibited by PPOH-3.9, Figure 5(c), where $\mathrm{G}^{\prime}>\mathrm{G}^{\prime \prime}$ over the entire frequency range measured. No crossover of $\mathrm{G}^{\prime}$ and $\mathrm{G}^{\prime \prime}$ was observed indicating that $\tau$ was longer than $50 \mathrm{~s}$ (i.e, the reciprocal of the lowest frequency, $\omega=0.02 \mathrm{~s}^{-1}$ ). That result is not due to simple molecular weight effects, since the molecular weight is comparable to that of PP and the other PPOH-x copolymers. Instead, the network-like behavior is a consequence of the supramolecular network formed by the intermolecular H-bonding. Based on the non-linear rheology results discussed later in this paper, one would expect that the $G^{\prime}, G^{\prime \prime}$ crossover occurs at a frequency of $\omega \sim 6 \times 10^{-4} \mathrm{~s}^{-1}$. 
The $\mathrm{G}^{\prime}$ and $\mathrm{G}^{\prime \prime}$ data at the lower frequencies for PPOH-3.9 in Figure 5(c) were linear with equal power-law dependencies, i.e., $\mathrm{G}^{\prime} \propto \omega^{0.44}, \mathrm{G}^{\prime \prime} \propto \omega^{0.44}$. Those results are consistent with the formation and persistence of a weak gel-like network, ${ }^{25-27}$ where the dynamic moduli are observed to become congruent and proportional to $\omega^{c}$ across the entire frequency range, $c$ being a constant. The presence of a gel-like network is attributed to the intermolecular H-bonding. In two previous papers, ${ }^{5,6}$ Gupta and coworkers suggested that microphase separation of hydroxyl-rich nanodomains may account for the network-like behavior of PPOH-3.9. Recently, molecular simulations by Misra et al. $^{22}$ for hydroxyl-modified polyethylenes indicated that $[\mathrm{OH}]-$ nanoclusters formed at a relatively low hydroxyl concentration. The LVE behavior of PPOH-3.9 is also consistent with the idea that the nanocluster phase acts as a multi-functional supramolecular crosslink to produce a transient network - in the case of Figure 5(c), with a network relaxation time greater than the experimental timescales used in those experiments. Unfortunately, evidence of the nanophase-separation could not be obtained from transmission electron microscopy, because of the crystallinity of the polymers which obscures other small features in the microstructure, or from small-angle X-ray scattering, because of the low electrondensity contrast between the $\mathrm{OH}$ nanoclusters and the amorphous hydrocarbon phase.

The relaxation times $(\tau)$ calculated from the inverse of the crossover frequency of the LVE data in Figure 5 are reported in Table 1. The reported relaxation time-molecular weight relationship for PP is $\tau_{\mathrm{t}} \propto \mathrm{M}_{\mathrm{w}}{ }^{3.6} \sim \mathrm{M}_{\mathrm{v}}{ }^{3.6}$, where $\tau_{\mathrm{t}}$ is the terminal relaxation time. ${ }^{8.9}$ Figure 6(a) is a $\log -\log$ plot of $\tau$ as a function of a normalized molecular weight, $\mathrm{M}_{\mathrm{v}} /\left(\mathrm{M}_{\mathrm{v}}\right)_{\mathrm{PP}}$, and the dashed line is the $\tau \propto \mathrm{M}_{\mathrm{v}}{ }^{3.6}$ prediction. Clearly, the relaxation times of the PPOH-x copolymers do not correlate well with simply molecular weight. Figure 6(b) plots the same relaxation time data as in Figure 6(a) against the $[\mathrm{OH}]$ concentration and, recognizing that the error in the relaxation time 
calculations summarized in Table 1 is probably no better than $10-20 \%$, the plot shows a strong relationship, $\tau \propto[\mathrm{OH}]^{3.8}$, if molecular weight differences were ignored. The blue crosses in Figure 6(b) are the relaxation time predictions based only on the difference between the $M_{v}$ for the copolymers and PP, i.e., these are points on the dashed line in Figure 6(a). Although a simple correlation between $\tau$ and $[\mathrm{OH}]$ is shown in Figure 6(b), it is likely that both $\mathrm{M}_{\mathrm{v}}$ and $[\mathrm{OH}]$ play a role in determining the rheological properties. This is discussed further in the Non-linear Viscoelastic Properties section below.
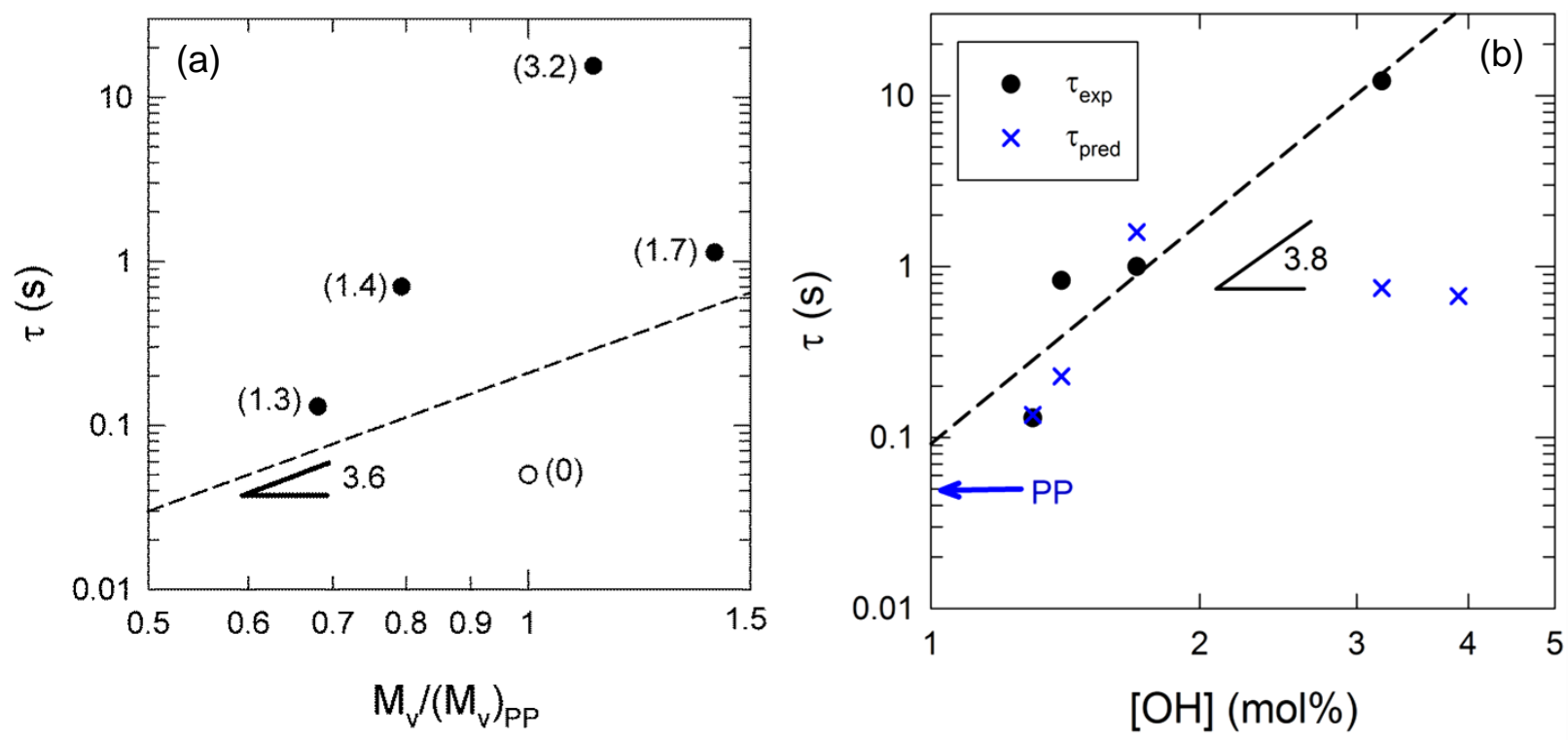

Figure 6. (a) Relaxation time of $\mathrm{PP}$ and $\mathrm{PPOH}-\mathrm{x}$ copolymers as a function of normalized viscosity-average molecular weight. The numbers in parentheses are the $[\mathrm{OH}]$ concentrations of the samples and the dashed line is the relaxation time prediction for $\tau \propto \mathrm{M}_{\mathrm{v}}{ }^{3.6}$. (b) Relaxation time of PP and PPOH-x copolymers as a function of $[\mathrm{OH}]$ concentration. The blue crosses are the relaxation time predictions for the PPOH-x copolymers if $\tau \propto \mathrm{M}_{\mathrm{v}}{ }^{3.6}$. The dashed line, which has a slope of 3.8, is the least squares fit of the experimental data (filled circles).

The H-bonding interactions between the $\mathrm{OH}$ groups increased the elasticity and viscosity of the PPOH copolymers as a result of forming transient physical crosslinks that provide a 
network and suppress the chain mobility. Even though the concentration of $\mathrm{OH}$ groups in $\mathrm{PPOH}$ copolymers was small, similar effects of H-bonding increasing the polymer melt elasticity and viscosity have been observed in other systems, e.g., Weiss and Stamato ${ }^{28}$ reported about an order of magnitude increase in the zero-shear viscosity of a high molecular weight polystyrene melt at $150^{\circ} \mathrm{C}$ by grafting only $1.2 \mathrm{~mol} \%$ sulfonic acid groups to the PS.

The flow activation energy of PP and the PPOH-x copolymers, $\Delta \mathrm{E}$, was determined by using Arrhenius analyses, ${ }^{29}$ equations (3) and (4), of the temperature dependence of the frequency shift factors $\left(a_{T}\right)$ used to construct the LVE mastercurves for PP and the PPOH copolymers,

$$
\begin{gathered}
\tau_{t}=A \exp (\Delta E / R T) \\
\ln a_{T}=\ln \left(\tau_{t} / \tau_{t, r}\right)=\ln \left(\eta_{o} / \eta_{o, r}\right)=\frac{\Delta E}{R}\left(\frac{1}{T}-\frac{1}{T_{r}}\right)
\end{gathered}
$$

where $\tau_{t}$ is the terminal relaxation time, $\eta_{\mathrm{o}}$ is the zero-shear viscosity, $T$ is the temperature of interest, $\mathrm{T}_{\mathrm{r}}$ is a reference temperature and $\mathrm{R}$ is the universal gas constant. Example Arrhenius plots for PP, PPOH-1.7 and PPOH-3.9 are shown in Figure 7. Similar plots were obtained for the other PPOH-x polymers. The linearity of the plots indicates an activated process for flow and the results are summarized in Table $1 . \Delta \mathrm{E}$ is a measure of the potential energy barrier to translation of the monomer segments and should be independent of molecular weight ${ }^{30-32}$ and the molecular weight distribution $^{12,33}$ for a specific homopolymer above a critical molecular weight of 2-3 times the entanglement molecular weight, $\mathrm{M}_{\mathrm{e}}$. For all the polymers studied in this research $\mathrm{M} \gg>$ $\left(\mathrm{M}_{\mathrm{e}}\right)_{\mathrm{PP}}=5500 \mathrm{~g} / \mathrm{mol}^{34}$ 


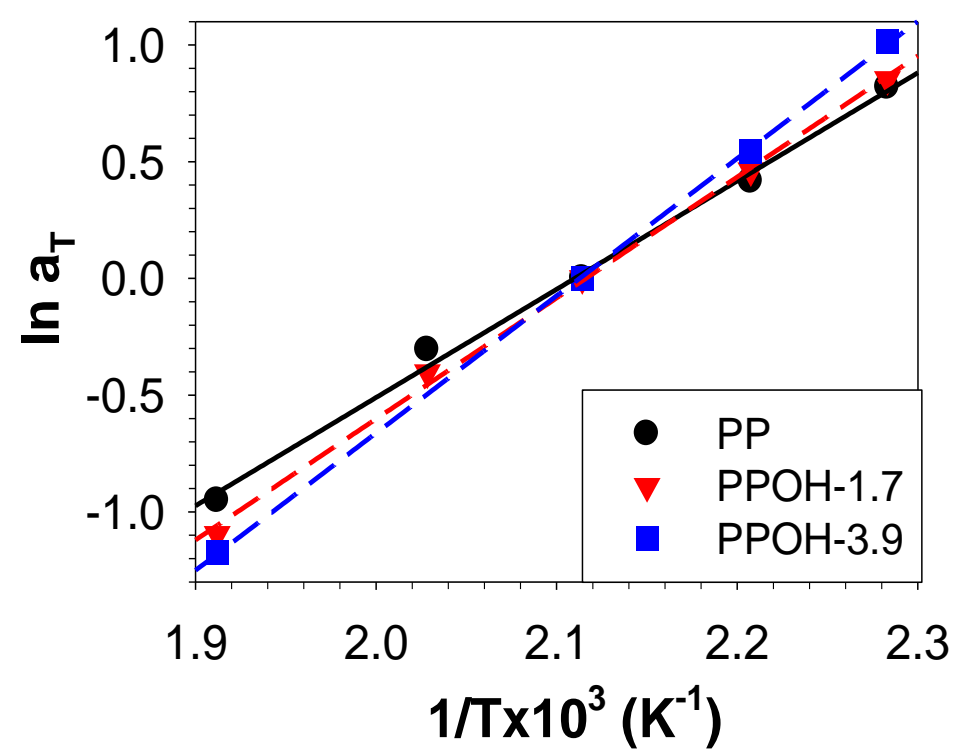

Figure 7. Arrhenius plots for the temperature dependence of the horizontal shift factors $\left(\mathrm{a}_{\mathrm{T}}\right)$.

An activation energy of $38.6 \mathrm{~kJ} / \mathrm{mol}$ calculated for PP is consistent with reported literature values. ${ }^{35,36} \Delta \mathrm{E}$ increased with increasing $[\mathrm{OH}]$ concentration, up to $52.4 \mathrm{~kJ} / \mathrm{mol}$ for PPOH-3.2, but for the PPOH-3.9 sample $\Delta \mathrm{E}$ either did not change appreciably or possibly decreased slightly to $48.9 \mathrm{~kJ} / \mathrm{mol}$. Since $\Delta \mathrm{E}$ is not sensitive to molecular weight, the increase of the potential energy barrier to translation of the polymer repeat units must be due to the increase in concentration of the transient crosslinks formed by the intermolecular hydrogen bonds. It is tempting to attribute the "decrease" of $\Delta \mathrm{E}$ as the hydroxyl concentration increased from 3.2 to $3.9 \mathrm{~mol} \%$ to the occurrence of nanophase-separation. However, additional experiments are needed with hydroxyl concentrations greater than $3 \mathrm{~mol} \%$ to determine if the differences of the $\Delta \mathrm{E}$ 's for PPOH-3.2 and PPOH-3.9 are real or due to the uncertainty of the activation energy calculation, which as for the relaxation time is probably at least $10-20 \%$. 
Non-linear Viscoelastic Properties. The steady-shear flow curves for the PP and the PPOH-x copolymers are plotted in Figure 8(a). Each of the flow curves showed a region of constant viscosity, the zero-shear viscosity $\left(\eta_{\mathrm{o}}\right)$, at low shear rates that was followed by a powerlaw shear thinning region. A Carreau mode ${ }^{37}$ was fit to the experimental data,

$$
\eta(\dot{\gamma})=\eta_{0}\left[1+(\lambda \dot{\gamma})^{2}\right]^{\left.\frac{n-1}{2}\right)}
$$

where $\lambda$ is a relaxation time that denotes the transition from Newtonian-like viscosity behavior to non-Newtonian behavior and $n$ is a flow behavior index. For all the polymers studied here $n<1$, which indicates pseudoplastic behavior. The fitting parameters $\eta_{0}, \lambda$, and $n$ for the different polymers are summarized in Table 1.
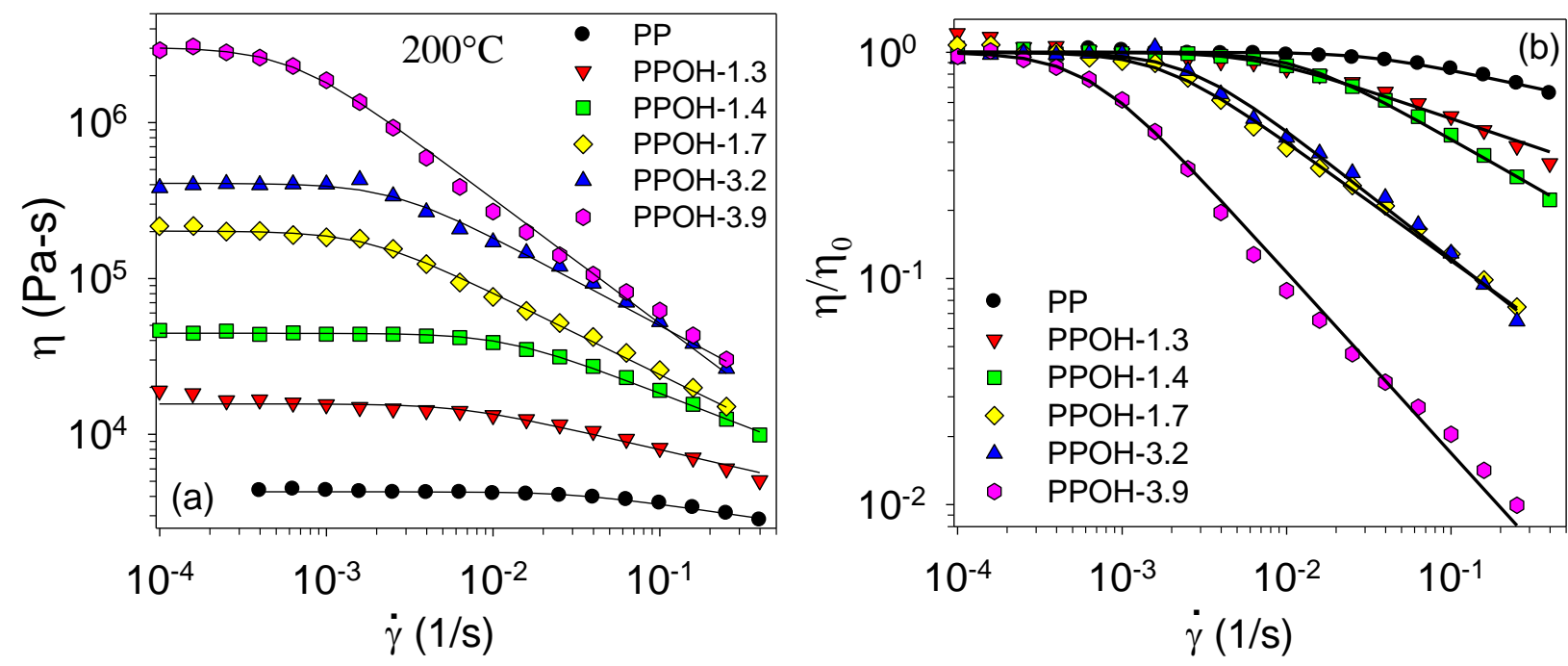

Figure 8. (a) Steady-shear viscosity, and (b) normalized steady-shear viscosity, as a function of shear rate for $\mathrm{PP}$ and $\mathrm{PPOH}$ copolymers at $200^{\circ} \mathrm{C}$. The solid lines represent the Carreau model fit of equation (5) to the experimental data. 
The zero-shear viscosities of the PPOH-x copolymers were significantly higher than that of the PP, increasing by three orders of magnitude as the $[\mathrm{OH}]$ concentration increased from 0 (i.e., PP) to $3.9 \mathrm{~mol} \%$. For entangled polymers the zero shear viscosity is related to the terminal relaxation time by equation $(6),{ }^{24}$

$$
\tau_{t}=J_{e}^{o} \eta_{0}
$$

where $J_{e}^{o}$ is the recoverable compliance, which is a measure of the energy stored during flow. For associating polymers, such as ionomers, $J_{e}^{o}$ should be independent of the concentration or type of the associating species, because in the terminal region the associations are short-lived with an association relaxation time much shorter than $\tau_{\mathrm{t} .}{ }^{7}$ As a consequence the supramolecular interactions support no stress in the terminal region, so regardless of the functionalization of the ionomer $\eta_{0} \propto \tau_{\text {t }}$. That result is also expected to apply to the PPOH-x copolymers, so it should be no surprise that like the relaxation time, as discussed earlier in this paper, $\eta_{0}$ for the PPOH-x copolymers also does not follow the usual 3.6 power-law dependence on molecular weight. Similarly, as was the case with the relaxation time (see earlier discussion), $\eta_{0}$ is very sensitive to the hydroxyl concentration.

Although broadening the MWD affects the elasticity and viscosity of polymer melts, all of the MWD values calculated for the $\mathrm{PP}-\mathrm{OH}$ samples were very large (>10). Given the uncertainty of the effect of H-bonding on the molecular weight measurements discussed earlier in this paper, the values for MWD probably are probably the least accurate. In addition, calculations made using the $\eta_{0}$ correlations with $\mathrm{M}_{\mathrm{w}} / \mathrm{M}_{\mathrm{n}}$ and $\mathrm{M}_{\mathrm{z}} / \mathrm{M}_{\mathrm{w}}$ indicate that the effects of MWD on $\eta_{0}$ were much less significant that the effects of hydrogen bonding. 
The shear viscosity data in Figure 8(a) are replotted in Figure 8(b), where the viscosities of each polymer were normalized by its zero-shear rate viscosity. That normalization removes the effects of molecular weight on the viscosity in the linear region, i.e., the Newtonian-like region at low shear rates. That approach also emphasizes the differences in the non-Newtonian behavior of PP and the PPOH-x copolymers. The most evident difference is that the magnitude of the slope $|n-1|$ of $\eta(\dot{\gamma})$, where $n$ is the power-law index, increased with increasing hydroxyl concentration. The reason for that is the increased shear-sensitivity of the supramolecular network. The increase in $\eta_{\mathrm{o}}$ as the $\mathrm{OH}$ concentration increased is due to the formation of the $\mathrm{H}$ bonded network. However high temperatures, e.g., $200^{\circ} \mathrm{C}$, weaken the H-bonds, and at high shear rates the supramolecular network is disrupted. For low shear rates, some H-bonds are broken by the stress applied by the deformation of the chains. However, an isolated (non $\mathrm{H}$ bonded) hydroxyl group pays a large enthalpic penalty to be in the hydrocarbon phase, and if the relaxation time of association of the hydroxyl groups is faster than the experimental time $\left(\dot{\gamma}^{-1}\right)$, the free hydroxyl group quickly reforms a H-bond with its former associated group or with another hydroxyl group. Under those conditions, the supramolecular network is in a state of dynamic equilibrium, that is for every H-bond broken another one forms, and $\eta=\eta_{\mathrm{o}}$. At higher shear rates, however, when the association time is slower than $\dot{\gamma}^{-1}$, the equilibrium between $\mathrm{H}$ bonded hydroxyl groups, which provide the supramolecular crosslinks, and non H-bonded, free hydroxyl groups that do not provide crosslinks shifts towards the latter state, which lowers the viscosity. The negative slope of the shear-thinning region of the flow curve increased with increasing $\mathrm{OH}$ concentration as a result of a greater contribution of the supramolecular network to $\eta_{0}$ - that is, the concentration of H-bonds increased with increasing hydroxyl concentration, so 
when that network weakens, at high temperature and high shear rate, the concentration of $\mathrm{H}$ bonds disrupted is also highest for the polymers with higher hydroxyl concentrations.

Figure 8(b) also shows that the shear rate at which non-linear behavior occurred, $\dot{\gamma}_{\mathrm{c}}$, decreased with increasing hydroxyl concentration. $\dot{\gamma}_{c}$ is related to the relaxation time, $\lambda$, in the Carreau model by $\lambda=\left(\dot{\gamma}_{c}\right)^{-1}$, and the values of $\lambda$ are listed in Table 1 . There is some scatter of the relaxation time data, but in general $\lambda$ increased exponentially with increasing $\mathrm{OH}$ concentration. The origin of $\lambda$ for PP is related to chain disentanglement in the melt, however, the meaning of $\lambda$ is less apparent for the PPOH copolymers. Disentanglement of polymer chains in the copolymers is suppressed by the physical crosslinks formed by the H-bonding of the hydroxyl groups. Thus, the non-linearity in the flow behavior requires a cooperative disruption of multiple H-bonds. Although perhaps an oversimplification, the increase of the relaxation time with increasing hydroxyl concentration is a consequence of more H-bonds that must be disrupted before the chains can disentangle, which effectively requires more shear of the melt. A broader MWD for the PPOH copolymers may also produce stronger shear thinning behavior than PP, ${ }^{9}$ but decoupling the contributions to shear thinning from H-bond disruption and MWD is not possible from the limited number of samples used in this research.

The last column in Table 1 lists the apparent molecular weights of the PPOH-x copolymers. These values were calculated by assuming that the entanglement density per chain in the polymer melt was higher than that based on the actual molecular weight of the polymer as measured by either GPC or solution viscosity. In effect, equation (7) calculates what molecular weight (i.e., $\mathrm{M}_{\mathrm{app}}$ ) PP would produce for the experimental zero-shear rate viscosity values, which 
are higher than expected due to the additional physical network produced by the H-bonding interactions.

$$
M_{a p p}=M_{w, P P} \times\left(\frac{\eta_{0}}{\eta_{0, P P}}\right)^{\frac{1}{3.6}}
$$

The calculated values of $\mathrm{M}_{\text {app }}$ are summarized in Table 1. Note that $\mathrm{M}_{\text {app }}$ for PPOH-1.4 was about three times its actual $\mathrm{M}_{\mathrm{v}}$, and for PPOH-3.9 it was an order of magnitude greater than the actual $\mathrm{M}_{\mathrm{v}}$. These effective molecular weights are remarkable considering that they result simply from H-bonding interactions of a small amount $(<4$ mol\%) of hydroxyl groups.

A theoretical treatment for the dynamics of associating polymers is provided by the Leibler-Rubinstein-Colby (LRC) model. ${ }^{38}$ The LRC model predicts that the terminal relaxation time of an associating polymer scales as,

$$
\tau_{t} \cong\left(\frac{N}{N_{e}}\right)^{1.5} \frac{2 S^{2} \tau_{d i s s}}{\left(1-\frac{9}{p}+\frac{12}{p^{2}}\right)}
$$

where $\mathrm{N}$ and $\mathrm{N}_{\mathrm{e}}$ are the number of monomer units in the polymer chain and an entangled segment respectively, $S$ is the total number of associating groups per chain, $\tau_{\text {diss }}$ is the lifetime of an association, and $\mathrm{p}$ is the average fraction of groups that are associating at any given time. The exponent of 1.5 in the first term on right side of equation (8) comes from two scaling relationships of reptation time: $\tau_{t} \propto D_{\text {self }}^{-1} \propto N^{-2}$ where $D_{\text {self }}$ is the self-diffusion coefficient of a polymer chain, and $\tau_{\mathrm{t}} \propto \mathrm{N}^{3.5}$ which is a general phenomenological observation for many polymers. The LRC model assumes that (a) the associations are dimeric, (b) the polymer chains are monodisperse, and (c) the number of associations are less than the number of entanglements 
$\left(\mathrm{N}_{\mathrm{e}}<\mathrm{N}_{\mathrm{s}}<\mathrm{N}\right)$. The LRC theory is shown to be in good agreement with the experimental data on polybutadienes bearing randomly attached pendant urazole groups where H-bonding associations occur through the $\mathrm{N}-\mathrm{H}^{\cdots} \mathrm{O}$ linkages.

It can be further shown that $S \propto \mathrm{M}_{\mathrm{w}} \times[\mathrm{A}]$, where [A] is the molar concentration of associating groups. Also, since $\tau_{\mathrm{t}} \propto \mathrm{N}^{3.6} \propto \mathrm{M}_{\mathrm{w}}{ }^{3.6}$ for PP and $\tau_{t}=J_{e}^{o} \eta_{0}$, equation (8) can be reduced to the following equation for PPOH-x copolymers,

$$
\eta_{0} \propto M_{w}^{3.6}[O H]^{2} \approx K M_{v}^{3.6}[O H]^{2}
$$

where $\mathrm{K}$ is an equilibration constant and the units for $\eta_{0}, \mathrm{M}_{\mathrm{v}}$ and $[\mathrm{OH}]$ are $(\mathrm{Pa} \cdot \mathrm{s}),(\mathrm{g} / \mathrm{mol})$ and mol\%, respectively. Equation (9) assumes that the lifetime of an association $\left(\tau_{\text {diss }}\right)$ and the fraction of associating groups (p) are independent of the molar concentration of associating groups. These assumptions seem reasonable based on the experimental data for polybutadienes with pendant urazole groups where $\tau_{\text {diss }}$ did not appear to change, and p increased by $20 \%$ as the molar concentration of urazole groups increased from 0.5 to $7.5 \mathrm{~mol} \% .^{38,39}$ A non-linear leastsquares fit of equation (9) to the viscosity data in Table 1 produced a value of $\mathrm{K}=2 \times 10^{-15}$ $\mathrm{Pa} \cdot \mathrm{s} \cdot \mathrm{mol}^{3.6} \cdot \mathrm{g}^{-3.6}$. Figure 9 shows that equation (9) does a reasonable job at representing the dependencies of $\eta_{0}$ on the molecular weight and hydroxyl concentration, and that the experimental results are consistent with the predictions of the LRC model. This is a bit surprising especially considering that the two assumptions in the LRC model, namely, monodisperse chains and number of associations less than the number of entanglements, are not necessarily valid for the PPOH-x copolymers. 


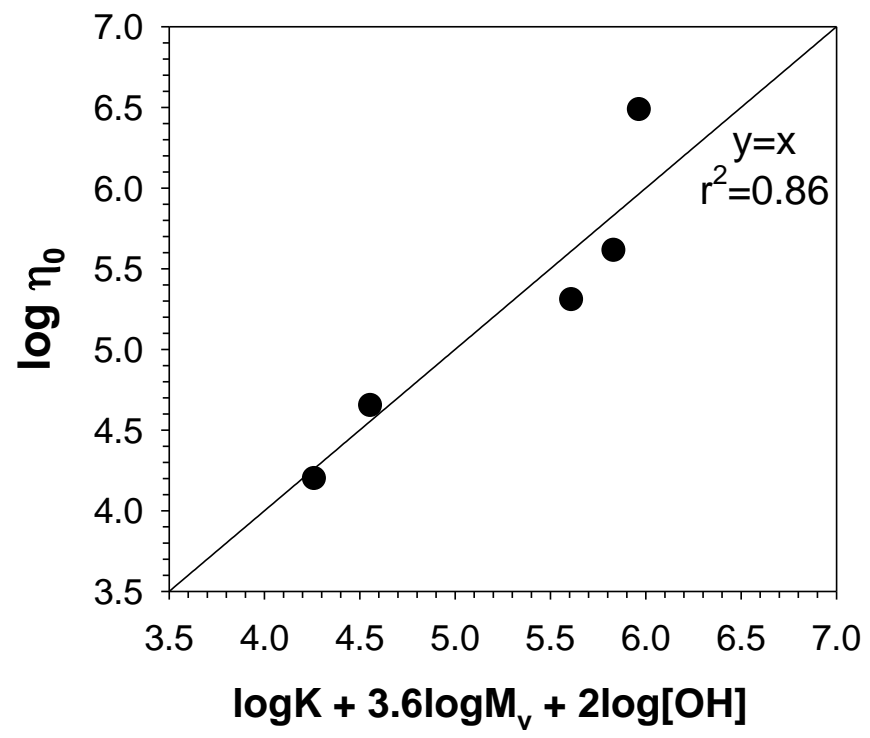

Figure 9. Comparison of the zero-shear viscosity $(\mathrm{Pa} \cdot \mathrm{s})$ of $\mathrm{PPOH}-\mathrm{x}$ copolymers at $200^{\circ} \mathrm{C}$ with predictions from the LRC model given by equation (9).

Figure 10 compares the steady shear, $\eta(\dot{\gamma})$, and complex viscosities, $\eta^{\star}(\omega)$, for PP and PPOH copolymers obtained from SAOS and steady-shear measurements. The Cox-Merz rule ${ }^{40}$ predicts that $\eta(\dot{\gamma})=\eta^{\star}(\omega)$ when $\dot{\gamma}=\omega$ and shows this is the case for a hydroxyl concentration less than 3 mol\%. However, overlap between $\eta(\dot{\gamma})$ and $\eta^{\star}(\omega)$ was not achieved for deformation rates between about $10^{-2}-10^{0} \mathrm{~s}^{-1}$ for PPOH-3.2 and $\mathrm{PPOH}-3.9$. Interestingly, the Cox-Merz rule is reported to fail for thermorheologically complex systems, such as immiscible polymer blends, cross-linked or gelled systems and other systems where phase separation occurs, ${ }^{41-43}$ and it is very tempting to relate the failure of the Cox-Merz rule for the PPOH copolymers with the onset of the nanophase separation of the hydroxyl groups discussed earlier in this paper. 


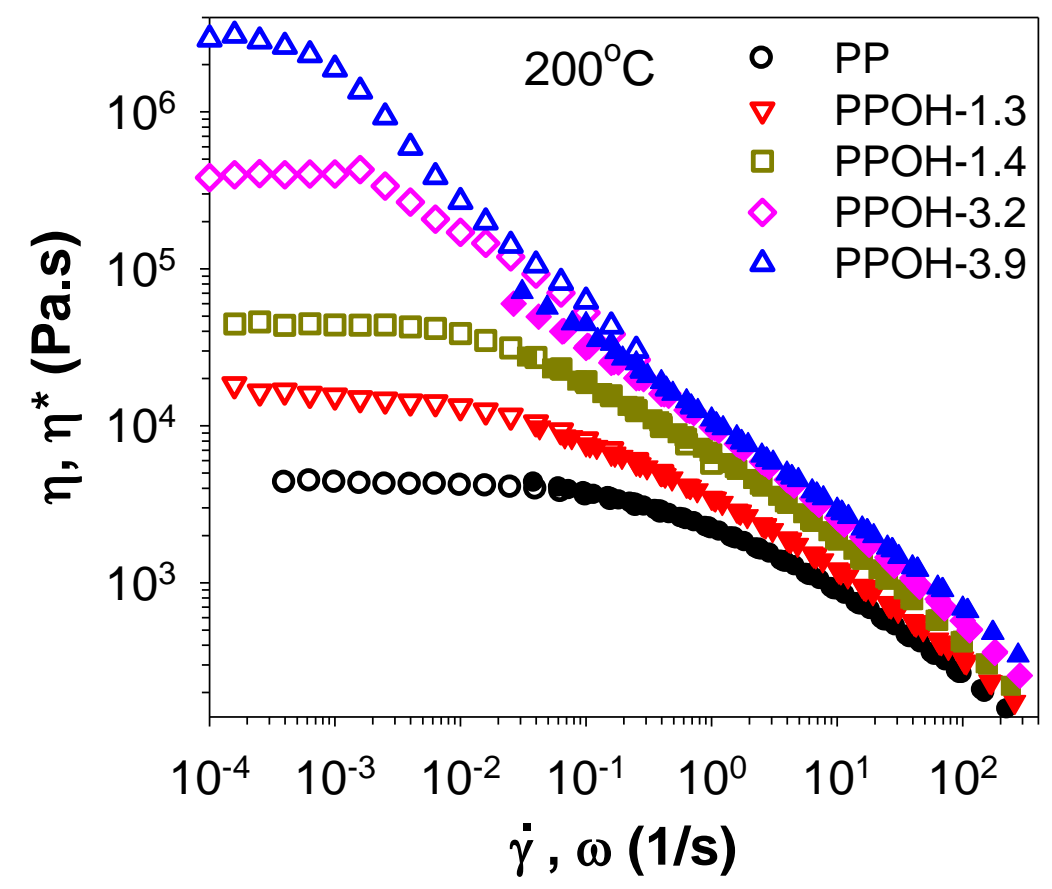

Figure 10. Comparison of the complex viscosity (filled symbols) and steadyshear viscosity (open symbols) for PP and $\mathrm{PPOH}$ copolymers at $200^{\circ} \mathrm{C}$.

The shear rate dependence of the first normal stress difference $\left(\mathrm{N}_{1}\right)$ and first normal stress difference coefficient $\left(\psi_{1}\right)$ for $\mathrm{PP}$ and the $\mathrm{PPOH}$ copolymers is shown in Figure 11. A comparison with Figure 8(a) indicates that the data in Figure 11 lies in the non-linear region. $\psi_{1}$ increased with increasing hydroxyl concentration, which indicates higher melt elasticity of the PPOH copolymers. The reported dependence of $\psi_{1}$ on the molecular weight of entangled PP is even stronger than that of the zero-shear viscosity, $\psi_{1,0} \propto \mathbf{M}^{7},{ }^{9}$ where $\psi_{1,0}$ is the zero-shear first normal stress coefficient. Although values of $\psi_{1,0}$ cannot be determined from Figure 11, as with the behavior of $\eta_{0}$ for the PPOH-x copolymers, the dependence of $\psi_{1}$ was not what was expected for PP and it depended on the hydroxyl concentration as well as the molecular weight. The remarkable aspect of these data is that an order of magnitude higher elasticity than PP results 
from the presence of only $3.2-3.9 \mathrm{~mol} \%$ hydroxyl groups. The origin of this additional elasticity is the $\mathrm{H}$-bonding interactions, which is consistent with the conclusions discussed earlier in this paper for the SAOS measurements of $\mathrm{G}^{\prime}$.

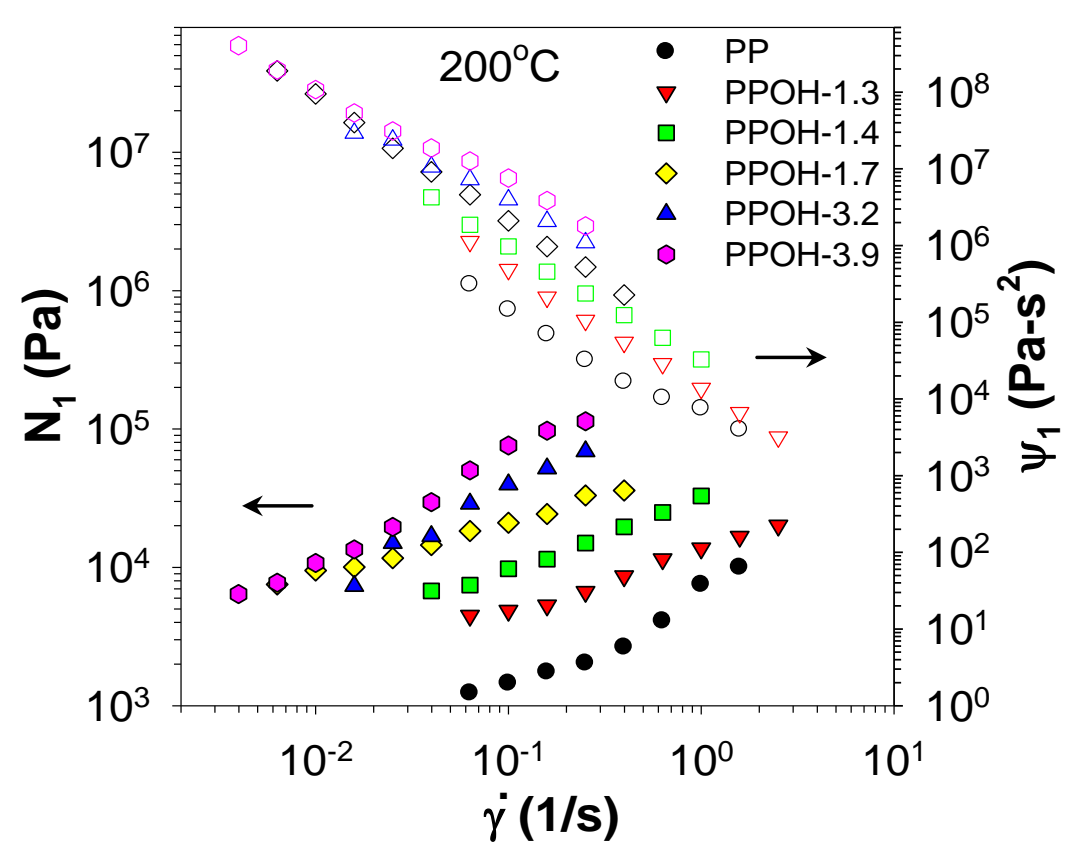

Figure 11. First normal stress difference $\left(\mathrm{N}_{1}\right)$ (closed symbols) and first normal stress difference coefficient $\left(\psi_{1}\right)$ (open symbols) obtained from steady shear measurements on $\mathrm{PP}$ and $\mathrm{PPOH}$ copolymers at $200^{\circ} \mathrm{C}$.

The zero-shear first normal stress coefficient is related to the zero-shear viscosity as, ${ }^{24}$

$$
\psi_{1,0}=2 \eta_{0}^{2} J_{e}^{0}
$$

As discussed before, for associating polymers $J_{e}^{0}$ is independent of the concentration or type of the associating species. Therefore, from equations (9) and (10), $\psi_{1,0}$ is expected to follow the following relationship according to the LRC theory,

$$
\psi_{1,0} \approx K^{\prime} M_{v}^{7.2}[\mathrm{OH}]^{4}
$$


where the units for $\psi_{1}, \mathrm{M}_{\mathrm{v}}$ and $[\mathrm{OH}]$ are $\left(\mathrm{Pa} \cdot \mathrm{s}^{2}\right),(\mathrm{g} / \mathrm{mol})$ and $\mathrm{mol} \%$, respectively. Since the values of $\psi_{1,0}$ could not be accessed experimentally, the above equation was fit to the $\psi_{1}$ data in Figure 11 at the experimental shear rate of $\dot{\gamma}=0.063 \mathrm{~s}^{-1}$, but the fitting failed as shown in Figure 12(a). However, a non-linear least-squares fit of the empirical equation,

$$
\psi_{1}=K^{\prime} M_{v}^{a}[O H]^{b}
$$

to the same data in Figure 12 (a) yielded $\mathrm{K}=0.14 \mathrm{~Pa} \cdot \mathrm{s} \cdot \mathrm{mol} \cdot \mathrm{g}^{-1}, \mathrm{a}=1.3$ and $\mathrm{b}=1.5$. The quality of that fit shown in Figure 12(b) indicates a reasonable approximation of $\psi_{1}$ by equation (12). A similarly good fit of the data at the highest shear rate used, $\dot{\gamma}=0.251 \mathrm{~s}^{-1}$, was also obtained with the same exponent for $\mathrm{M}_{\mathrm{v}}$, but an exponent of 1.7 for $[\mathrm{OH}]$. Although the $\psi_{1}$ data fall in the nonlinear flow region where the H-bonding is severely disrupted, it still exhibits a strong dependence on the hydroxyl concentration.
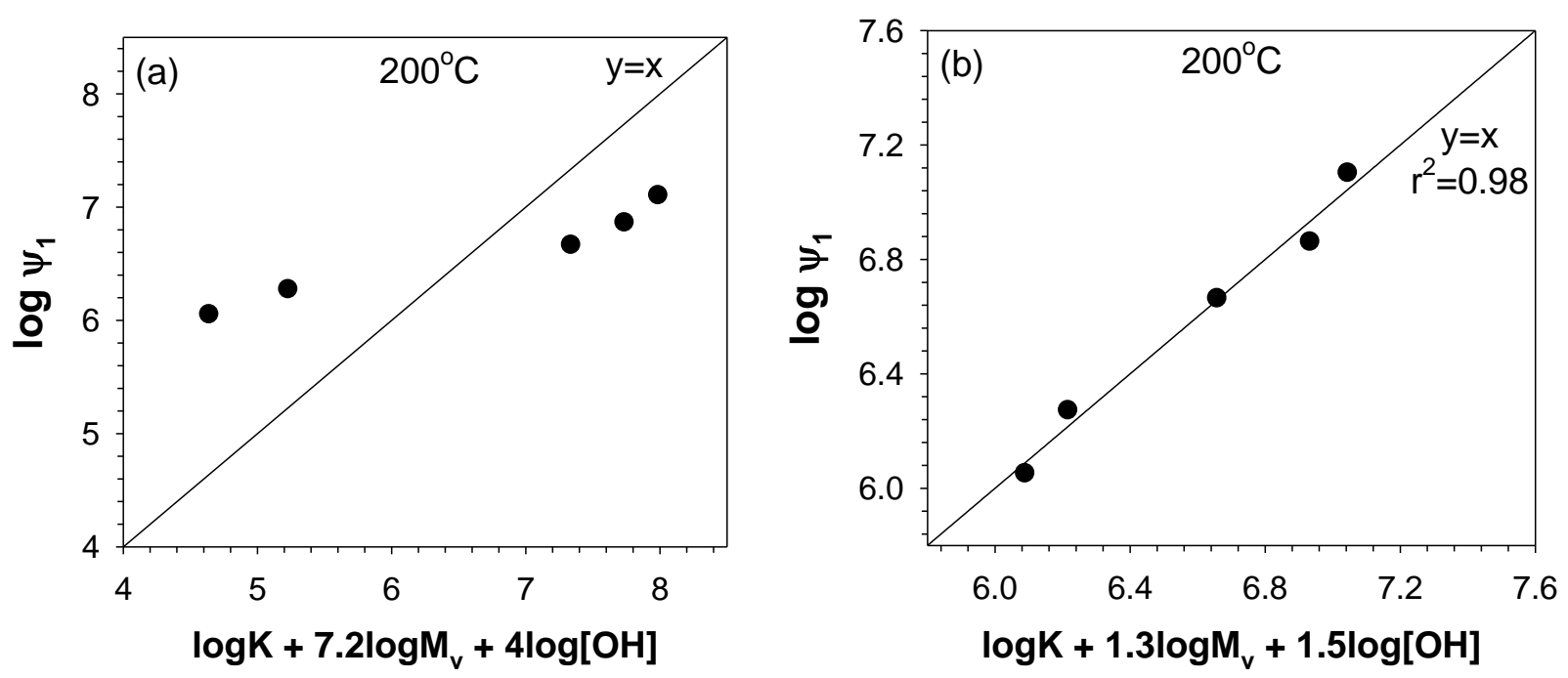

Figure 12. Comparison of the experimental data for the first normal stress difference coefficient $\left[\mathrm{Pa} \cdot \mathrm{s}^{2}\right]$ at $\dot{\gamma}=0.063 \mathrm{~s}^{-1}, 200^{\circ} \mathrm{C}$ for PPOH-x copolymers with the predictions from (a) LRC model represented by equation (11), and (b) empirical relation represented by equation (12). 


\section{Conclusions}

The introduction of $1.3-3.9$ mol\% of 10-hydroxy-1-undecenyl comonomer onto the backbone of isotactic polypropylene significantly increased the viscoelastic moduli of PP in the melt state. This was a result of $\mathrm{H}$-bonding interactions between the pendant hydroxyl groups present in the comonomer. The H-bonding persisted at melt temperatures up to at least $250^{\circ} \mathrm{C}$, though the $\mathrm{H}$-bond strength and the number of $\mathrm{H}$-bonded groups decreased with increasing temperature. Within the linear deformation limit, the viscosity and elasticity of the PPOH-X copolymers were higher than an unmodified PP of the same molecular weight. This was attributed to the formation of a secondary transient network formed by the H-bonded $\mathrm{OH}$ groups, in addition to a primary transient network of chain entanglements. The supramolecular H-bonded network produced apparent molecular weights of the PPOH-x copolymers 2-8 times higher than the molecular weights obtained by GPC or intrinsic viscosity measurements. The H-bonding was also responsible for a higher terminal-relaxation time for the PPOH-x copolymers than PP and shifted the terminal regime to lower frequencies. The effects of the H-bonded network on the viscoelastic properties of the modified PP were significant and comparable to the power-law relationships that those properties have on the molecular weight for unmodified PP.

The H-bonded secondary network was more sensitive to shear deformation than the primary network which was evident from the smaller strain limits of linear viscoelastic deformation for the PPOH-x copolymers compared to PP. The secondary network was also more sensitive to a thermal change as indicated by a higher flow activation energy as the hydroxyl concentration increased. The storage modulus of PPOH-3.9 was higher than the loss modulus at all temperatures and frequencies at $200^{\circ} \mathrm{C}$, which suggested the formation of a gel-like network 
due presumably to the aggregation of the hydroxyl groups and formation of nanophase rich domains that act as multi-functional physical crosslinks. That polymer, like the other PPOH-X copolymers did, however, exhibit viscous flow due to disruption of the supramolecular network with sufficient shear stress.

The effects of H-bonding on the polymer elasticity and viscosity were also observed under non-linear deformation, and those properties were also higher for the PPOH-x copolymers than for PP and increased with increasing hydroxyl concentration. The PPOH copolymers also exhibited stronger shear thinning characteristics, i.e. an earlier onset of shear thinning and a lower power-law index, than PP, because the flow was dominated by rupture of the H-bonded supramolecular network rather than by conventional chain disentanglements.

Despite the presence of $\mathrm{H}$-bonding and its variation with changing temperature, the timetemperature superposition (TTS) for the linear viscoelastic data of PPOH-x copolymers was applicable with an Arrhenius dependence of the horizontal shift factors on temperature. In conjunction with the TTS, compliance of the PPOH-x copolymers for $\mathrm{x}<3.2$ with the Cox-Merz rule suggested that these copolymers were thermorheologically simple. However, noncompliance of the PPOH-3.2 and PPOH-3.9 copolymers suggested that these copolymers were thermorheologically complex and exhibited a rheological behavior in between that of a homopolymer and an ionomer.

The higher viscosity and elasticity and greater shear sensitivity of the PPOH-X copolymers compared with PP suggest that those materials may be more conducive for biaxial stretching of thin films in the melt state. That conclusion is important with regard to the objective of this research that was discussed earlier in the Introduction section, namely evaluating the ability to biaxially orient PPOH-x into thin films for evaluation in capacitors. Our initial results ${ }^{44}$ 
confirm that the uniaxial/biaxial orientation of $\mathrm{PPOH}-\mathrm{x}$ melts can easily be achieved with equipment currently used to manufacture biaxially oriented PP (BOPP). A future paper will describe the melt extrusion and structure development upon biaxial stretching of thin film of PPOH-x.

\section{Acknowledgment}

The authors acknowledge the financial support for this work through a Multidisciplinary University Research Initiative (MURI) grant from the Office of Naval Research (Contract No. N00014-10-1-0944). We are also grateful to Prof. E. Bryan Coughlin and Dr. Brian Cromer at the University of Massachusetts, Amherst, for providing the high temperature GPC data. 


\section{References}

1. Barshaw, E. J.; White, J.; Chait, M. J.; Cornette, J. B.; Bustamante, J.; Folli, F.; Biltchick, D.; Borelli, G.; Picci, G.; Rabuffi, M. IEEE. T. Magn. 2007, 43, 223-225.

2. Wang, C. C.; Ramprasad, R. J. Mater. Sci. 2011, 46, 90-93.

3. Rabuffi, M.; Picci, G. IEEE T. Plasma. Sci. 2002, 30,1939-1942.

4. Yuan, X.; Matsuyama, Y.; Chung, T. C. Macromolecules 2010, 43, 4011-4015.

5. Gupta, S.; Yuan, X.; Chung, T. C. M.; Kumar, S.; Cakmak, M.; Weiss, R. A. Macromolecules 2013, 46, 5455-5463.

6. Gupta, S.; Yuan, X.; Chung, T. C. M.; Cakmak, M.; Weiss, R. A. Polymer 2014, 55, 924-935.

7. R. A. Register and R. K. Prud'homme. "Melt Rheology" in Ionomers: Synthesis, structure, properties and applications. Tant, M. R.; Mauritz, K. A.; Wilkes, G. L. Chapman and Hall, New York, 1997, pp 223-233.

8. Brandrup, J.; Immergut, E. H.; Grulke, E. A. (Eds.). Polymer Handbook $4^{\text {th }}$ ed.; John Wiley and Sons: New York, 1999.

9. Dealy, J. M.; Wissbrun, K. F. Melt Rheology and Its Role in Plastics Processing: Theory and Applications; Van Nostrand Reinhold: New York, 1990.

10. Stadler, F. J.; Piel, C.; Kaschta, J.; Rulhoff, S.; Kaminsky, W.; Munstedt, H. Rheol. Acta 2006, $45,755-764$.

11. Vega, J. F.; Santamaria, A.; Munoz-Escalona, A.; Lafuente, P. Macromolecules 1998, 31, $3639-3647$.

12. Wasserman, S. H.; Graessley, W. W. Polym. Eng. Sci. 1996, 36, 852-861.

13. Steeman, P. A. M. Rheol. Acta 1998, 37, 583-592. 
14. Zeichner, G. R.; Patel, P. D. Proc. $2^{\text {nd }}$ World Conference Chem. Eng. 1981, 6, 9.

15. Buslov, D. K.; Sushko, N. I.; Tretinnikov, O. N. Polym. Sci. A. 2011, 53, 1121-1127.

16. Steiner, T. Angew. Chem. Int. Ed. 2002, 41, 48-76.

17. Rozenberg, M.; Loewenschuss, A.; Marcus, Y. Phys. Chem. Chem. Phys. 2000, 2, 2699-2702.

18. Skrovanek, D. J.; Howe, S. E.; Painter, P. C.; Coleman, M. M. Macromolecules 1985, 18, $1676-1683$.

19. Skrovanek, D. J.; Painter, P. C.; Coleman, M. M. Macromolecules 1986, 19, 699-705.

20. Coleman, M. M.; Lee, K. H.; Skrovanek, D. J.; Painter, P. C. Macromolecules 1986, 19, 2149-2157.

21. Wang, C. C.; Pilania, G.; Ramprasad, R.; Agarwal, M.; Misra, M.; Kumar, S.; Yuan, X.; Chung, T. C. M. Appl. Phys. Lett. 2013, 102, 152901.

22. Misra, M.; Agarwal, M.; Sinkovitis, D.; Kumar, S. K.; Wang, C.; Pilania, G.; Ramprasad, R.; Weiss, R. A.; Yuan, X.; Chung, T. C. M. Macromolecues 2014, 47, 1122-1129.

23. Van Gurp, M.; Palmen, J. Rheol Bull 1998, 67, 5-8.

24. Ferrry, J. D. Viscoelastic Properties of Polymers $3^{\text {rd }}$ ed. John Wiley and Sons: New York, 1980.

25. Chambon, F.; Winter, H. H. J. Rheol. 1987, 31, 683-697.

26. Winter, H. H.; Morganelli, P.; Chambon, F.; Macromolecules 1988, 21, 532-535.

27. Muller, R.; Gerard, E.; Dugand, P.; Rempp, P.; Gnanou, Y. Macromolecules 1991, 24, $1321-1326$.

28. Weiss, R. A.; Stamato, H. Polym. Eng. Sci., 1989, 29, 134-139. 
29. Glasstone, S.; Laidler, K.; Eyring, H. The Theory of Rate Processes. Viscosity and Diffusion. McGraw-Hill: New York, 1941. Ch 9:477-551.

30. Wang, J.; Porter, R. S. Rheol. Acta 1995, 34, 496-503.

31. Jordens, K.; Wilkes, G. L.; Janzen, J.; Rohlfing, D. C.; Welch, M. B. Polymer 2000, 41, $7175-7192$.

32. Mayrick, R. G.; Sieglaff, C. L. J. Appl. Polym. Sci. 1965, 9, 3917-3927.

33. Ansari, M.; Hatzikiriakos, S. G.; Sukhadia, A. M.; Rohlfing, D. C. Rheol. Acta 2011, 50, $17-27$.

34. Fetters, L. J.; Lohse, D. J.; Graessley, W. W. J. Polym. Sci. Pol. Phys. 1999, 37, 10231033.

35. Mavridis, H.; Shroff, R. N. Polym. Eng. Sci. 1992, 32, 1778-1791.

36. Alle, N.; Lyngaae-Jorgensen, J. Rheol. Acta 1980, 19, 94-103.

37. Carreau, P. J. Trans. Soc. Rheol. 1972, 16, 99-127.

38. Leibler, L.; Rubinstein, M. and Colby, R. H. Macromolecules 1991, 24, 4701-4707.

39. Stadler, R. and de Lucca Freitas, L. Colloid Polym. Sci. 1988, 266, 1095.

40. Cox, W. P.; Merz, E. H. J. Polym. Sci. 1958, 28, 619-622.

41. Han, J. H.; Choi-Feng, C.; Li, D.; Han, C. D. Polymer 1995, 36, 2451-2462.

42. Weiss, R. A.; Agarwal, P. K. J. Appl. Polym. Sci. 1981, 26, 449-462.

43. Han, J. H.; Feng, J.; Choi-Feng, C.; Han, C. D. Polymer 1995, 36, 155-167.

44. Offenbach, I.; Gupta, S.; Chung, T. C. M.; Weiss, R. A.; Cakmak, M. Macromolecules $\mathbf{2 0 1 5}, 48,6294-6305$. 


\title{
Influence of Hydrogen Bonding on the Melt Rheology of Polypropylene
}

\author{
Sahil Gupta ${ }^{1 \dagger}$, Xuepei Yuan ${ }^{2}$, T. C. Mike Chung ${ }^{2}$, M. Cakmak ${ }^{1}$ and R. A. Weiss ${ }^{1 *}$ \\ ${ }^{1}$ Department of Polymer Engineering, The University of Akron, Akron, OH 44325 \\ ${ }^{2}$ Department of Materials Science and Engineering, The Pennsylvania State University, \\ University Park, PA, 16802
}

\section{Graphical Abstract}

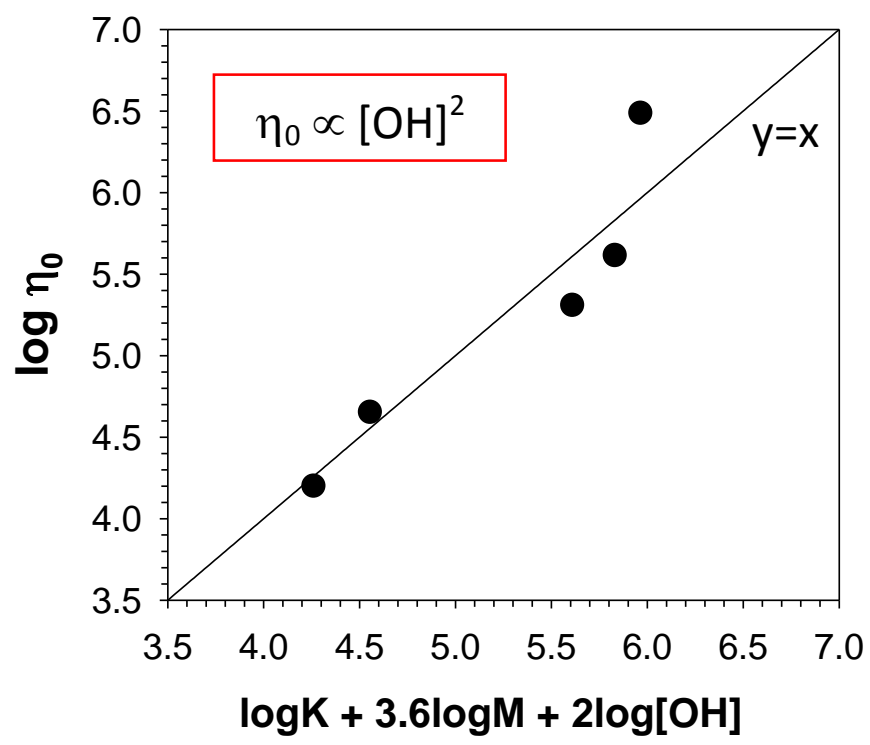

